15. El Juzgado Casero, herausgegeben von Anónimo

16. El Murmurador imparcial y observador desapasionado de las locuras y despropósitos de los hombres, herausgegeben von Francisco Mariano Nipho y Cagigal

17. El Observador, herausgegeben von José Marchena

18. El Pensador, herausgegeben von Joseph Clavijo y Faxardo

19. El Regañón general, herausgegeben von Ventura Ferrer

20. El Teniente del Apologista, herausgegeben von Eugenio Habela Patiño

21. La Pensadora gaditana, herausgegeben von Beatriz Cienfuegos

22. La Pensatriz salmantina, herausgegeben von Escolástica Hurtado

\title{
8.2 ANHANg 2 - QUANTITATIVe Auswertung
}

\subsubsection{Frauen- und Männerbild-Markups in den französischsprachigen Wochenschriften}

Tabelle 6: Frauen- und Männerbild-Markups in den französischsprachigen Wochenschriften.

\begin{tabular}{|c|c|c|c|c|c|c|}
\hline & Zeitschrift, Erscheinungsjahr & $\begin{array}{c}\text { Ge- } \\
\text { samt- } \\
\text { zahl }\end{array}$ & $\begin{array}{l}\text { Frauen- } \\
\text { bild } \\
\text { (abso- } \\
\text { lut) }\end{array}$ & $\begin{array}{c}\text { Män- } \\
\text { nerbild } \\
\text { (abso- } \\
\text { lut) }\end{array}$ & $\begin{array}{c}\text { Frauen- } \\
\text { bild } \\
\text { (rela- } \\
\text { tiv) }\end{array}$ & $\begin{array}{l}\text { Män- } \\
\text { nerbild } \\
\text { (rela- } \\
\text { tiv) }\end{array}$ \\
\hline 1 & Le Misantrope, 1711-12 & 89 & 14 & 8 & $15,7 \%$ & $9,0 \%$ \\
\hline 2 & Le Censeur, 1714 & 43 & 8 & 5 & $18,6 \%$ & $11,6 \%$ \\
\hline 3 & La Bagatelle, 1718-19 & 98 & 17 & 6 & $17,3 \%$ & $6,1 \%$ \\
\hline 4 & Le Spectateur français, 1721-24 & 25 & 9 & 0 & $36,0 \%$ & $0,0 \%$ \\
\hline 5 & Le Spectateur suisse, 1723 & 2 & 2 & 0 & $100,0 \%$ & $0,0 \%$ \\
\hline 6 & Le Spectateur inconnu, 1723-24 & 10 & 1 & 1 & $10,0 \%$ & $10,0 \%$ \\
\hline 7 & $\begin{array}{l}\text { Le Nouveau Spectateur fr., 1723- } \\
25\end{array}$ & 28 & 13 & 4 & $46,4 \%$ & $14,3 \%$ \\
\hline 8 & L'Indigent philosophe, 1727 & 7 & 2 & 0 & $28,6 \%$ & $0,0 \%$ \\
\hline 9 & La Spectatrice, 1728-29 & 15 & 8 & 0 & $53,3 \%$ & $0,0 \%$ \\
\hline 10 & Le Cabinet du philosophe, 1734 & 11 & 4 & 0 & $36,4 \%$ & $0,0 \%$ \\
\hline 11 & La Spectatrice danoise, $1748-50$ & 29 & 5 & 1 & $17,2 \%$ & $3,4 \%$ \\
\hline 12 & Le Spectateur moderne, 1753 & 1 & 1 & 0 & $100,0 \%$ & $0,0 \%$ \\
\hline 13 & Le Nouveau Spectateur, 1758-60 & 108 & 48 & 16 & $44,4 \%$ & $14,8 \%$ \\
\hline 14 & Le Monde comme il est, 1760 & 60 & 38 & 12 & $63,3 \%$ & $20,0 \%$ \\
\hline 15 & Le Spectateur François, 1776 & 5 & 1 & 0 & $20,0 \%$ & $0,0 \%$ \\
\hline \multirow[t]{2}{*}{16} & $\begin{array}{l}\text { Le Spectateur fr. avant la Rév., } \\
1795\end{array}$ & 61 & 14 & 5 & $23,0 \%$ & $8,2 \%$ \\
\hline & Gesamt & 592 & 185 & 58 & & \\
\hline
\end{tabular}

Quelle: Eigene Darstellung. 


\subsubsection{Frauen- und Männerbild-Markups in den spanischsprachigen Wochenschriften}

Tabelle 7: Frauen- und Männerbild-Markups in den spanischsprachigen Wochenschriften.

\begin{tabular}{|c|c|c|c|c|c|c|}
\hline & Zeitschrift, Erscheinungsjahr & $\begin{array}{c}\text { Ge- } \\
\text { samt- } \\
\text { zahl }\end{array}$ & $\begin{array}{c}\text { Frauen- } \\
\text { bild } \\
\text { (abso- } \\
\text { lut) }\end{array}$ & $\begin{array}{l}\text { Män- } \\
\text { nerbild } \\
\text { (abso- } \\
\text { lut) }\end{array}$ & $\begin{array}{c}\text { Frauen- } \\
\text { bild } \\
\text { (rela- } \\
\text { tiv) }\end{array}$ & $\begin{array}{l}\text { Män- } \\
\text { nerbild } \\
\text { (rela- } \\
\text { tiv) }\end{array}$ \\
\hline 1 & El Duende Crítico, 1735-36 & 21 & 0 & 0 & $0,0 \%$ & $0,0 \%$ \\
\hline 2 & El Murmurador imparcial, 1761 & 1 & 0 & 0 & $0,0 \%$ & $0,0 \%$ \\
\hline 3 & El Duende especulativo, 1761 & 19 & 0 & 0 & $0,0 \%$ & $0,0 \%$ \\
\hline 4 & El Pensador, 1762-63 & 86 & 14 & 6 & $16,3 \%$ & $7,0 \%$ \\
\hline 5 & El Escritor sin título, 1763 & 11 & 1 & 0 & $9,1 \%$ & $0,0 \%$ \\
\hline 6 & $\begin{array}{l}\text { El Amigo y Corresponsal del } \\
\text { Pensador, } 1763\end{array}$ & 4 & 0 & 2 & $0,0 \%$ & $50,0 \%$ \\
\hline 7 & La Pensadora gaditana, 1763-64 & 52 & 21 & 17 & $40,4 \%$ & $32,7 \%$ \\
\hline 8 & El Belianís literario, 1765 & 7 & 0 & 0 & $0,0 \%$ & $0,0 \%$ \\
\hline 9 & La Pensatriz salmantina, 1777 & 1 & 1 & 0 & $100,0 \%$ & $0,0 \%$ \\
\hline 10 & El Curioso Entretenido, 1779-80 & 8 & 2 & 0 & $25,0 \%$ & $0,0 \%$ \\
\hline 11 & El Censor, $1781-87$ & 167 & 12 & 0 & $7,2 \%$ & $0,0 \%$ \\
\hline 12 & El Juzgado Casero, 1786 & 1 & 1 & 0 & $100,0 \%$ & $0,0 \%$ \\
\hline 13 & El Apologista Universal, 1786-88 & 16 & 0 & 0 & $0,0 \%$ & $0,0 \%$ \\
\hline 14 & $\begin{array}{l}\text { El Corresponsal del Censor, } \\
1786-88\end{array}$ & 51 & 0 & 0 & $0,0 \%$ & $0,0 \%$ \\
\hline 15 & $\begin{array}{l}\text { El Corresponsal del Apologista, } \\
1787\end{array}$ & 1 & 0 & 0 & $0,0 \%$ & $0,0 \%$ \\
\hline 16 & El Observador, 1787 & 6 & 0 & 0 & $0,0 \%$ & $0,0 \%$ \\
\hline 17 & El Duende de Madrid, 1787-88 & 7 & 1 & 0 & $14,3 \%$ & $0,0 \%$ \\
\hline 18 & El Teniente del Apologista, 1788 & 1 & 0 & 0 & $0,0 \%$ & $0,0 \%$ \\
\hline 19 & El Argonauta Español, 1790 & 26 & 6 & 2 & $23,1 \%$ & $7,7 \%$ \\
\hline 20 & El Catón compostelano, 1800 & 22 & 3 & 1 & $13,6 \%$ & $4,5 \%$ \\
\hline \multirow[t]{2}{*}{21} & El Regañón general, 1803-04 & 62 & 8 & 0 & $12,9 \%$ & $0,0 \%$ \\
\hline & Gesamt & 570 & 70 & 28 & & \\
\hline
\end{tabular}

Quelle: Eigene Darstellung. 


\subsubsection{Textsorten in den französischsprachigen Wochenschriften}

Tabelle 8: Absolute Häufigkeiten der Textsorten in den Nummern mit Frauen- und Männerbild-Markup in den französischsprachigen Wochenschriften.

\begin{tabular}{|c|c|c|c|c|c|c|c|c|c|c|c|c|c|c|c|c|}
\hline & 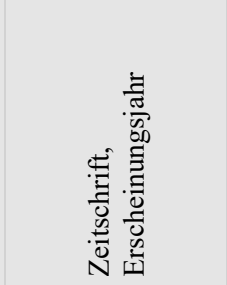 & 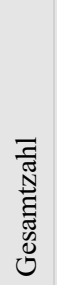 & 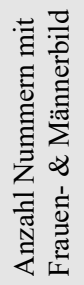 & 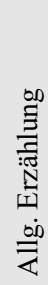 & 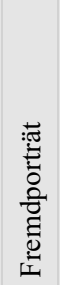 & 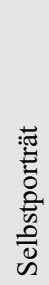 & $\frac{80}{.05}$ & 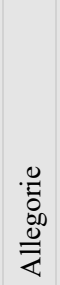 & 胥 & $\begin{array}{l}\overline{\mathbb{D}} \\
\text { ब्ञ }\end{array}$ & 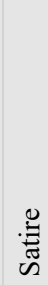 & 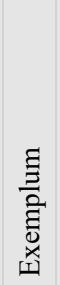 & $\frac{0}{0}$ & 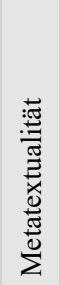 & 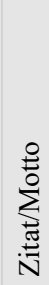 & $\stackrel{4}{\mathscr{D}}$ \\
\hline & $\begin{array}{l}\text { Le Misantrope, } \\
1711-12\end{array}$ & 89 & 14 & 2 & 3 & 1 & 1 & & & & & 1 & & 10 & 10 & 2 \\
\hline 2 & Le Censeur, 1714 & 43 & 9 & 3 & 7 & 1 & & & & & & 1 & & 8 & 1 & 7 \\
\hline 3 & $\begin{array}{l}\text { La Bagatelle, } \\
1718-19\end{array}$ & 98 & 17 & 8 & 3 & & 5 & 3 & 1 & & & 1 & 2 & 11 & 3 & 3 \\
\hline 4 & $\begin{array}{l}\text { Le Spectateur } \\
\text { français, 1721-24 }\end{array}$ & 25 & 9 & 9 & 6 & 6 & 7 & & & & & 2 & & 8 & & 6 \\
\hline 5 & $\begin{array}{l}\text { Le Nouv. Specta- } \\
\text { teur fr., 1723-25 }\end{array}$ & 28 & 15 & 2 & 3 & 2 & 2 & & & & & 6 & & & 5 & 5 \\
\hline 6 & $\begin{array}{l}\text { La Spectatrice, } \\
1728-29\end{array}$ & 15 & 8 & 7 & 4 & 4 & 4 & & 1 & & & & & 7 & 1 & \\
\hline 7 & $\begin{array}{l}\text { Le Cabinet du } \\
\text { philosophe, } 1734\end{array}$ & 11 & 4 & 2 & 2 & & 3 & 2 & 1 & & & 2 & 1 & 4 & 1 & \\
\hline 8 & $\begin{array}{l}\text { La Spectatrice } \\
\text { danoise, } 1748-50\end{array}$ & 29 & 5 & 2 & & 1 & 1 & & & & & & & 4 & 2 & 2 \\
\hline 9 & $\begin{array}{l}\text { Le Nouv. Specta- } \\
\text { teur, 1758-60 }\end{array}$ & 108 & 48 & 29 & 19 & 3 & 22 & & 1 & & & & & 35 & 22 & 36 \\
\hline 10 & $\begin{array}{l}\text { Le Monde com- } \\
\text { me il est, } 1760\end{array}$ & 60 & 39 & 32 & 11 & & 19 & 1 & & & & 1 & 1 & 32 & 10 & 27 \\
\hline & $\begin{array}{l}\text { Le Spectateur fr. } \\
\text { avant la Rév., } \\
1795\end{array}$ & 61 & 15 & 3 & 2 & & 2 & & & & & & & 1 & & 9 \\
\hline & Gesamt & 567 & 183 & 99 & 60 & 18 & 66 & 6 & 4 & 0 & 0 & 14 & 4 & 120 & 55 & 97 \\
\hline
\end{tabular}

Quelle: Eigene Darstellung. 


\subsubsection{Textsorten in den spanischsprachigen Wochenschriften}

Tabelle 9: Absolute Häufigkeiten der Textsorten in den Nummern mit Frauen- und Männerbild-Markup in den spanischsprachigen Wochenschriften.

\begin{tabular}{|c|c|c|c|c|c|c|c|c|c|c|c|c|c|c|c|c|}
\hline & 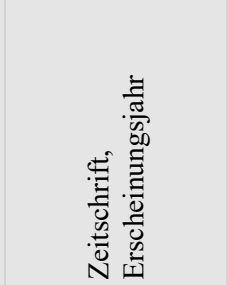 & 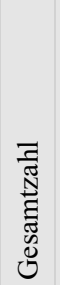 & 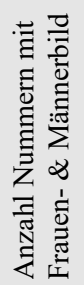 & 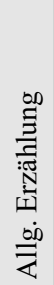 & 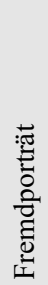 & 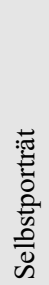 & $\frac{\infty}{0}$ & 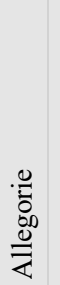 & 志 & $\begin{array}{l}\overline{\mathcal{D}} \\
\text { 疍 }\end{array}$ & 营 & 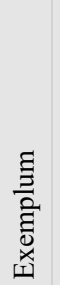 & . & 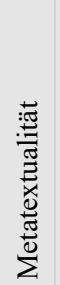 & 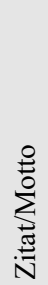 & $\stackrel{4}{\bar{m}}$ \\
\hline 1 & $\begin{array}{l}\text { El Pensador, } \\
1762-63\end{array}$ & 86 & 16 & 10 & 10 & 6 & 4 & & 1 & & & 5 & & 12 & 1 & 11 \\
\hline 2 & $\begin{array}{l}\text { La Pensadora } \\
\text { gaditana, 1763- } \\
64\end{array}$ & 52 & 25 & 16 & 3 & 10 & 2 & & & 3 & & 18 & & 22 & 15 & 13 \\
\hline 3 & $\begin{array}{l}\text { El Censor, 1781- } \\
87\end{array}$ & 167 & 12 & 6 & 3 & 4 & 1 & & 1 & & 2 & 1 & & 10 & 12 & 12 \\
\hline 4 & $\begin{array}{l}\text { El Argonauta } \\
\text { español, } 1790\end{array}$ & 26 & 7 & 22 & & & 1 & & & & & 1 & 1 & 3 & 7 & 1 \\
\hline 5 & $\begin{array}{l}\text { El Catón com- } \\
\text { postelano, } 1800\end{array}$ & 22 & 3 & 1 & 2 & 1 & & & & 1 & & 3 & & 3 & 2 & \\
\hline 6 & $\begin{array}{l}\text { El Regañón gene- } \\
\text { ral, 1803-04 }\end{array}$ & 62 & 8 & 3 & 3 & & 1 & & & & & 2 & & 6 & & 8 \\
\hline & Gesamt & 415 & 71 & 58 & 21 & 21 & 9 & 0 & 2 & 4 & 2 & 30 & 1 & 56 & 37 & 45 \\
\hline
\end{tabular}

Quelle: Eigene Darstellung. 